\title{
P363: Qualitative and quantitative evaluation of medical waste products in Côte d'Ivoire
}

\author{
MJ Bitty ${ }^{*}$, OP Kamelan, YB Coha, JD Seka, M Samba \\ From 2nd International Conference on Prevention and Infection Control (ICPIC 2013) \\ Geneva, Switzerland. 25-28 June 2013
}

\section{Introduction}

Medical waste is now a real public health problem because of their negative impacts on health and the environment. Since the studies in 2002, Côte d'Ivoire has not yet conducted a qualitative and quantitative assessment of medical waste generation. This makes it difficult to put in place a coherent strategy for waste management, planning and design of some management structures. This evaluation of medical waste reflects a desire to update the data for better decision making.

\section{Objectives}

The overall objective is to evaluate qualitatively and quantitatively the medical waste in Côte d'Ivoire.

\section{Specific Objectives}

Identify medical waste according to a typology; Know the amount of each type of medical waste; Make recommendations.

\section{Methods}

The structures are the structures of the health system in the private sector and the public. The selection of structures was carried out through a survey at 2 levels. All survey sites were monitored at least 3 times during the investigation. The collection includes two steps: sorting and weighing of waste. Each site was equipped with bins 27 and 80 liters of blue garbage bags (infectious medical waste and medical waste non-infectious), black garbage bags (waste comparable to domestic waste), safety box for sharp objects, spikes and / or sharp and a precision electronic balance (2 grams).

\section{Results}

The daily domestic production of medical waste in the public sector is estimated at $11,617,739 \mathrm{~g}$ or 11.62 tons. Domestic production in the private sector is estimated at $1,476,997 \mathrm{~g}$ per day, or 1.48 per ton. Infectious and hazardous wastes represent $59.39 \%$ of the medical waste. Côte d'Ivoire produces daily 13.1 tonnes of medical waste is estimated to be 4781.5 tonnes annually in all sectors.

\section{Conclusion}

Nearly $70 \%$ of medical waste is infectious and dangerous. The results are for the public sector, $809 \mathrm{~g} / \mathrm{bed} /$ day against $452 \mathrm{~g} /$ bed / day for the private sector. The national average is estimated at $630 \mathrm{~g} / \mathrm{bed} /$ day.

\section{Disclosure of interest}

None declared.

Published: 20 June 2013

doi:10.1186/2047-2994-2-S1-P363

Cite this article as: Bitty et al:: P363: Qualitative and quantitative evaluation of medical waste products in Côte d'Ivoire. Antimicrobial Resistance and Infection Control 2013 2(Suppl 1):P363. 